\title{
Gender Identity and Sex Roles in Marriage : a review
}

\author{
Avinash De Sousa ${ }^{1}$ \\ Janki Mehta ${ }^{2}$ \\ ${ }^{1}$ Consultant Psychiatrist and Founder Trustee, Desousa Foundation, Mumbai. \\ ${ }^{2}$ Consultant Psychotherapist and Counsellor, Private Practice, Mumbai. \\ E-mail - avinashdes888@gmail.com
}

\begin{abstract}
The following review paper assesses the current state of gender identity and sex roles in marriage. The paper looks at the new and emerging gender perspective in modern marriages and the role of men and women with regard to stability and open communication in a marital relationship. The paper looks at both positive and negative communication in marital life and its role on marital stability. It also looks at the role of masculinity and feminism in communication patterns and how they affect communication patterns. The paper looks at cognition in sex roles as that is a new emerging area in marriage psychology research and thereby sums up the field of gender identity in marriage from a marital therapy and basic psychology perspective.
\end{abstract}

Key words : marriage, marital communication, sex roles, gender identity, masculinity.

\section{INTRODUCTION}

Characteristic patterns often emerge to define the roles of husbands and wives, especially when couples become distressed. Marital therapists frequently encounter distressed wives who complain of relationship discord but report being unable to convince their husbands to enter therapy. Interviews with husbands and wives also reveal gender-related patterns. For example, from wives we hear, "I can't stand that he's so damned unemotional and expects me to be the same. He lives in his head all the time, and he acts like anything that's emotional isn't worth dealing with". Their husbands respond, "When she comes after me like that, yapping like that, she might as well be hitting me with a bat.... No matter what I say it's no good. I try to keep my cool and be logical, but nothing works".

Understanding the nature of differences between husbands and wives in marriage and the origin of these differences requires careful study of happy and unhappy couples over time. There is a need to study the full range of marital satisfaction in order to determine whether observed differences result from sex differences, marital distress, or some interaction between the two. In addition, cross-sectional comparisons of distressed and non distressed couples may yield a different picture of husbands and wives than that which emerges from longitudinal study of relationships. Consequently, longitudinal investigations may reveal quite different information as a function of the 
stage of relationship that is studied. For example, variables that predict marital adjustment in the early years of marriage may not predict adjustment in later years.

An important challenge for researchers is to identify the proper domain of relational and/or individual variables to study. The current article addresses this challenge by examining how gender based behaviors and sex-role identity can further our understanding of gender differences in marriage. In the first section, we document gender differences in the behavioral correlates and the behavioral predictors of marital distress. The second section explores the utility of sex-role identity for understanding various aspects of marriage including marital behavior.

\section{GENDER DIFFERENCES IN MARITAL BEHAVIOR}

Our analysis of gender differences in the marital behavior of distressed and non-distressed couples focuses on communication. The rationale for emphasizing communication behaviors is two fold. First, spouses recognize communication as among the most important aspects of their relationship. Second, detailed interactional analyses of problem-solving discussions in distressed and non-distressed relationships have accounted for upward of $80 \%$ of the variance in the classification of couples as distressed or non-distressed [1].

According to social learning theory, distressed spouses will exchange too few positive behaviors and too many negative behaviors. As a correlate of declining positive sentiment toward the relationship and the spouse, partners engage in a number of negativistic cognitions to explain their relationship difficulties. Experiencing a surfeit of negative events and a paucity of positive interactions, and armed with cognitions detrimental to the relationship, marital distressed individuals experience a wide range of negative emotions, particularly anger, anxiety, and depression. Thus, the behaviors, cognitions, and emo $\neg$ tions of the couple become interwoven to constitute the phenomenon of marital distress.

It can be seen that spouses in distressed relationships display more disagreement, are more critical of their partners, and appear more contemptuous of each other than spouses in a happy marriage. Although several similarities in the behavior of distressed husbands and wives are apparent from the table, important differences also emerge. Discord seems to affect husbands and wives differently. In the problem-solving (high-conflict) situations studied, the behavior of distressed wives appears to be more negative than that of distressed husbands (and more negative than non-distressed wives and non-distressed husbands as well). They found that distressed wives displayed more noncompliance, put-downs, commands, and complaints. These differences in frequencies, although informative, do not tell us about the patterning or the structure of communication that characterizes husbands and wives [2].

Sequential analyses applied to codes describing a stream of behavior reveal how one partner's behavior is linked systematically to interactional antecedents. Several studies have assessed the sequential dependencies characterizing husbands and wives in distressed and non-distressed relationships. For distressed husbands and wives, and for non-distressed husbands, there was a strong likelihood of becoming a negative speaker if, while listening, negative affect was displayed. However, non-distressed wives were much less likely to become negative speakers after being negative listeners. Thus, non-distressed wives decrease the likelihood of long chains of negative exchange with their partners that are so characteristic of distressed marital interaction [3]. 
It seems safest to assume at this point that there are two genderrelated processes that are active in shaping the interactional behaviors of distressed and non-distressed couples in problem-solving discussion. It appears that non-distressed wives are willing and able to provide a nonnegative reply $t$ their partners' messages that they hear as negative and that distressed wives are unwilling and/or unable to provide a positive reply to their partners' negative messages. Although the magnitude of these differences between spouses is small, we believe that these subtle differences may be responsible for rather substantial differences in interactional outcomes. An infrequent positive reply from a non-distressed wife to a negative message may be all that is required to disrupt an escalating spiral of negative exchange.

The overall negativity displayed by distressed wives is notable and deserving of explanation. One fruitful avenue of investigation might be to assess wives' attributions for marital discord in general and for their husbands' behavior in particular as a mediator of their interactional behavior. Another possibility is to consider the likely consequences of the early stages of relationship discord during which wives appear to push for engagement. Assuming a social learning model, these marriages headed for distress will be characterized by inadequate relationship skills, and wives' attempts to maintain engagement are likely to lead to greater conflict and discord, from which distressed husbands are likely to retreat. As husbands withdraw further from the relationship, their wives are likely to see this withdrawal as yet another problem with the relationship. Husbands' withdrawal is perhaps an even greater issue than the more specific disagreements that were the source of initial discord. Similarly, the press to discuss relationship difficulties and the resultant conflict that will frequently ensue may become the overriding issues for distressed husbands. For both partners, there is likely to be a profound sense of frustration: all efforts aimed at achieving harmony have failed, unresolved problems remain, and the couple identifies their marriage as unhappy and troubled [4].

\section{COMMUNICATION BEHAVIORS THAT PREDICT A DECLINE IN SATISFACTION OVER TIME}

The data on predictors of marital distress can be organized around the two central themes, engagement for wives and with $\neg$ drawal for husbands. Husbands who are likely to experience a decline in relationship satisfaction appear to have begun to pull back from the relationship. In a nonproblem discussion, these husbands appear to experience their wives' behavior less posiᄀtively compared to husbands whose relationship satisfaction is maintained over time. In a problem discussion likely to generate conflict, the husbands' withdrawal is expressed as less criticism and disagreement. It is as if these husbands are trying to avoid engaging in overt conflict with their wives. Be $\neg$ cause this pattern is a predictor of relationship decline, the find $\neg$ ings suggest that the relative absence of criticism and disagree $\neg$ ments from husbands is a marker not of accord but of a decision to maintain interactional calm even if problems do not receive the attention they deserve [5].

The behavior of wives in relationships that predict a decline in satisfaction appears to reflect a recognition of relationship problems and an attempt to keep their husbands engaged in interaction. In non-conflict discussions and problemsolving discussions, these wives evaluate their husbands' messages more positively they are more agreeing and more approving of their husbands, and they are more likely to reciprocate their partners' positive behaviors. In essence, these wives, like their 
husbands, appear sensitive to relationship conflict, but rather than withdrawing, they seek to soothe the relationship through positive exchanges. The behaviors of intimate partners in relationships that will, over time, decline in satisfaction are generally consistent with a social learning model of relationship adaptation. In the absence of relationship skills, particularly effective communication, and problem-solving skills, everyday issues are left unresolved and begin to accumulate. Early attempts to attribute difficulties to situational causes may begin to yield to more destructive thoughts that hold the partner responsible for difficulties. The partners are likely to feel less able to resolve relational difficulties, and in turn, lowered expectancies for successful problem solving may contribute to more destructive interpersonal processes [6].

\section{SEX-ROLE IDENTITY}

The above discussion demonstrates that there are meaningful gender differences in communication behavior among married couples. Why do these differences occur, and what is the basis for them? Although some of these gender-related differences might result from biological and physiological differences, many of the differences likely are learned. There are many socializing factors that teach males to behave in certain ways and females to behave in other ways, and gender differences in marriage reflect, to an extent, society's norms for male/female behavior within intimate heterosexual relationships. However, within each gender, there are meaningful individual differences, and some of these individual differences probably affect relationship behavior. The field of individual differences points to a vast array of variables that could be relevant for understanding relationship behavior. The task is to identify which individual difference variables account for gender differences in marriage [7].

Perhaps the most central individual difference variable to consider within this context is sex-role identity. Each person develops a sense of him- or herself as a male or female, and the specifics included within this sex-role identity differ from one person to the next. Thus, differences noted among males in marital interaction may reflect these various males' beliefs about what it means to be a male within a marriage. The concept of sex-role identity can be broken down further into the variables of masculinity and femininity. Although these variables have been defined and measured differently by various investigators, masculinity can be defined as those characteristics (behaviors, attitudes, emotions, etc.) that are typical of males and that separate them as a group from females. Likewise, femininity can be defined as those characteristics that are typical of females and that separate them as a group from males [8-9].

Traditionally, masculinity and femininity have been construed as bipolar opposites on a single dimension. As a result, any individual could be placed on this single masculinity/femininity dimension, ranging from extremely masculine at one end to extremely feminine at the other end. Each person can be assessed on masculinity, which ranges from "masculine" at one end to "not masculine" at the other end. The same individual also can be assessed on femininity, ranging from "feminine" to "not feminine." Although the specific attributes comprising masculinity and femininity vary somewhat according to the particular scales employed, there does seem to be some consistency in what is included within these concepts. Masculinity usually includes an instrumental, task, and achievement orientation; "masculine" persons typically have a high level of drive and ambition. They are assertive and are leaders. Femininity includes an attention to emotional and expressive aspects of life, including an emphasis on interpersonal relationships. "Feminine" individuals typically are responsible and generally have accepted society's norms for ethical behaviour [11]. 
By employing these two dimensions, each person's sex-role identity can be viewed as that individual's level of masculinity in conjunction with his or her level of femininity. Thus, an individual might be high on both masculinity and femininity; such persons have been referred to as androgynous. Similarly, an individual might be high on masculinity and low on femininity, demonstrating a stereotypic masculine-sex-typed identity. Conversely, an individual might be high on femininity and low on masculinity (feminine-sex-typed). Finally, a person might be low on both masculinity and femininity, termed undifferentiated. By considering sex-role identity, findings that are viewed currently as reflecting sex differences in marriage can be interpreted with greater clarity. That is, investigators can evaluate whether being a member of a given gender is what is important in understanding an individual's behavior within marriage, whether a given level of masculinity and/or femininity is important, or whether gender and sex-role identity interact in some manner related to marital functioning [12].

\section{SEX-ROLE IDENTITY AND MARITAL ADJUSTMENT}

The investigation of sex-role identity and marital functioning is in its infancy, and at present the most basic question is being asked: is sex-role identity related to level of marital adjustment? A number of studies show that, indeed, sex-role identity is correlated with level of marital adjustment. More specifically, higher levels of femininity are correlated with higher levels of marital adjustment, and although less consistent, greater degrees of masculinity are related to higher levels of marital adjustment. Unfortunately, these studies have been limited by at least two factors. Many of them are based on samples with a restricted range of marital adjustment and omit couples who are significantly marital distressed. Second, the samples are often too small to investigate the simultaneous impact of both spouses' sex-role identities on either person's marital adjustment [13].

\section{SEX-ROLE IDENTITY AND MARITAL BEHAVIOR}

As noted earlier, communication difficulties can account for a substantial portion of the variance in marital distress. Thus, one major way in which sexrole identity could influence marital functioning is via communication. At least two investigations to date confirm that sex-role identity is related to the ways that couples communicate. In both investigations, couples were instructed to resolve marital conflicts. These interactions were then coded by trained observers. Researchers have examined the frequency with which couples expressed various types of positive and negative communication and found that femininity was positively correlated with positive communications and negatively correlated with negative communications. Thus, overall, femininity was related to more effective communication between spouses [14].

Because negative communication appears to differentiate level of marital distress more consistently than does positive communication, authors have focused on couples' negative communication. They evaluated both the frequency of negative communication and negative communication sequences (i.e., negative communication from one spouse followed by negative communication from the partner) among maritally distressed couples. For couples that included feminine husbands, husbands and wives exhibited a lower frequency of negative communications. These same couples demonstrated fewer and shorter negative communication sequences. Finally, the more feminine the distressed wife was, the less likely she was to terminate a 
negative communication sequence. That is, feminine wives kept the negative interaction alive [15].

\section{SEX-ROLE IDENTITY AND COGNITION}

In recent years, researchers from a social learning perspective have recognized that marital happiness is not merely a function of both persons' behavior. This behavior is processed cognitively by both partners, and the ways that spouses think about each other's behavior can influence their relationship satisfaction. For example, whether a husband's late arrival from the office has a positive or negative impact on his wife might be determined by her interpretation that (1) he is avoiding her and the family or (2) he is working late to make extra money to provide for the family's needs. Several categories of cognitions (including selective attention, at $\neg$ tributions, expectancies, assumptions, and standards) appear to be related to level of marital adjustment and might therefore be examined with regard to sex-role identity.

At present there are no published investigations in this area, but recent analyses of data on causal attributions point to the for each partner. These norms are derived from a number of sources, but they are likely to be at least partially influenced by each individual's views of male and female sex roles. The major function of norms is to increase the efficiency of interactions by providing a predictable set of responses to familiar situations. Thus, by helping to organize and constrain behavior, sex-role norms can provide guidelines for behavior when new situations are encountered. An individual who rigidly adheres to stereotyped masculine or feminine sex roles may have the skills to maintain relationship quality only within a limited range of the situations encountered in marriage. When circumstances deviate significantly from this range, the sex-typed individual's repertoire of behavioral responses may not be flexible or extensive enough to accommodate to the novel situation. An androgynous individual, however, has access to both masculine and feminine behaviors and has a greater chance of being able to respond adaptively to a much wider range of situational demands than a rigidly sextyped individual. The undifferentiated individual, with a very narrow range of behavioral options, may be predictable from a normative perspective, but he/she may make minimal contributions to the relationship because of a restricted repertoire of potentially adaptive responses [16].

\section{EXCHANGE VALUE OF SEX ROLES IN MARRIAGE}

Whereas the normative perspective emphasizes the importance of predictability and order within marriage, social exchange theory focuses on the content of what each partner has to offer in the marriage. The central tenet of social exchange theory is that partners' evaluations of the costs and benefits of maintaining their marriage determine the degree of marital quality they experience. From this perspective, masculine and feminine sex-role behavior can be viewed as contributions or assets to the relationship. Thus, the greater the range of sex-role behaviors an individual possesses, the more valuable his or her sex role is to the marriage. Thus, relationships that require behaviors outside of the individuals' repertoire can be viewed as costs or potential sources of marital dysfunction [17].

An androgynous couple would, presumably, have the widest range of sex-role behaviors from which to draw in the face of the myriad of situations confronting a marriage. The advantages to be gained from the ability to exercise both masculine and feminine behaviors include enhanced access to instrumental and 
expressive behaviors that are important in relationship functioning. Previously discussed findings suggest that when a couple includes an undifferentiated individual who contributes neither a high level of masculine nor of feminine behavior, then both that person and that individual's spouse are likely to be dissatisfied with the relationship. Thus, the results could be interpreted to mean that each partner must be seen as making some form of significant contribution to the relationship for either person to be satisfied with the marriage [18].

\section{CONCLUSIONS}

Although the study of gender differences and sex-role identity in marital relationships is still in its infancy, the findings to date indicate clearly that these domains of investigation warrant fur $\neg$ ther consideration. Gender differences in behavior, particularly in the area of communication, suggest that males and females assume different roles as couples struggle with marital problems. The study of sex-role identity in marital relationship indicates that both masculinity and femininity can be viewed as relationship assets to couples. The behavioral, cognitive, and emotional correlates of masculinity and femininity within a marital relationship and how these might affect marital adjustment have been reviewed. Finally, the role that androgyny might play in (1) providing predictability across a range of marital situations, (2) serving as an asset in a cost/benefit analysis of the relationship, and (3) contributing to an egalitarian relationship with regard to power, has been discussed.

Admittedly, many of the theoretical interpretations provided for gender differences and sex-role findings are speculative at this time. What is critical is that we begin to realize that a consistent body of empirical findings is beginning to emerge. Consequently, now is the time to consider these findings in terms of existing theories of marital functioning and to supplement or alter these theories where necessary to recognize that gender differences and sex-role identity are likely to be major influences on couples' day-to-day functioning and long-term relationship adjustment.

\section{REFERENCES}

1. Acitelli LK. Gender differences in relationship awareness and marital satisfaction among young married couples. Personal Soc Psychol Bull 1992;18:102-110.

2. Barber JS, Axinn WG. Gender role attitudes and marriage among young women. Sociol Quart 1998;39:11-32.

3. Baxter LA, Montgomery BM. Relating: Dialogues and dialectics. New York: Guilford Press ; 1996.

4. Brehm SS. Intimate relationships ( $2^{\mathrm{ND}}$ ed.) New York: McGraw-Hill; 1992.

5. Bmbacher, TH. Family relations: Challenges for the future. Marr Fam Living 1998;56:236259.

6. Burchardt CR. Readings in rhetorical criticism. State College PA: Strata Publishing Company ; 1995.

7. Burr E, Dunn S, Farquhar N. Women and the language of inequality. Soc Educ 1972;36:841-863.

8. Canary DJ, Stafford L. Relational maintenance strategies and equity in marriage. Communication Monographs 1992;59:243-267.

9. Chakraborty R, Schwartz RJ. Selective neutrality of surname distribution in an immigrant Indian community of Houston, Texas. Am J Hum Biol 1990;2:1-15. 
10. Fitzpatrick MA. Between husbands and wives. Newbury Park: CA: Sage ; 1998.

11. Frazier PA, Esterly E. Correlates of relationship beliefs: Gender, relationship experience and relationship satisfaction. J Soc Personal Relation 1990;7:331- 352.

12. Harrigan JA, Lucie KS. Attitudes about gender bias in language: A re-evaluation. Sex Roles 1998;19:129-141.

13. Horst EA, Doherty WJ. Gender, power, and intimacy. J Fem Fam Ther 1998;6:63-85.

14. Knudson-Martin C, Mahoney AR. Gender dilemmas and myths in the construction of marital bargains: Issues for marital therapy. Fam Process 1995;35:137-152.

15. Larson JH, Hammond $\mathrm{CH}$, Harper JM. Perceived equity and intimacy in marriage. J Mar Fam Therapy 1998;24:487-506.

16. Matthews B, Beaujot R. Gender orientations and family strategies. Rev Sociol Anthropology $1997 ; 34: 415-428$.

17. Regan PC, Berscheid E. Gender differences in characteristics desired in a potential sexual and marriage partner. J Psychol Human Sexuality 1998;9:25-37.

18. Tannen D. You just don't understand: Women and men in conversations. New York: William Morrow ; 1990.

Acknowledgements - Nil

Conflict of Interest - Nil

Funding - Nil 